\title{
Service Needs of the Homeless Mentally III in Belfast
}

\section{Sinéad McGilloway \& Michael Donnelly}

To cite this article: Sinéad McGilloway \& Michael Donnelly (2001) Service Needs of the Homeless Mentally III in Belfast, International Journal of Mental Health, 30:3, 50-56, DOI: 10.1080/00207411.2001.11449525

To link to this article: https://doi.org/10.1080/00207411.2001.11449525

册 Published online: 02 Sep 2015.

Submit your article to this journal $\pi$

山 Article views: 12

Q View related articles $₫$

4 Citing articles: 1 View citing articles 주제 


\section{Service Needs of the Homeless Mentally III in Belfast}

Despite the now well-established link between homelessness and mental ill health [1], little is known about whether or not the homeless mentally ill are receiving appropriate care and support or, indeed, what is the most effective way of delivering services to them. Research in this area is needed to address, among other things, persistent claims about how health and social services may be failing to provide adequate care for this population [2-4]. In the first part of the present study (see the preceding article), it was reported that 41 percent (165/401) of single homeless adults in Belfast had a mental health problem. A significant proportion had sufficiently poor levels of functioning and mental morbidity to suggest that they were not in contact with appropriate, if any, services or that existing provision of care was inadequate. Here we describe part two of the study, which was undertaken to assess the health, social care, and accommodation needs of 164 residents with mental health problems, with a view to estimating and planning future service requirements.

\section{Method}

Details on participants (including demographic characteristics) and settings are provided in the preceding paper. In part two of the study, three social workers and two community psychiatric nurses (CPNs) (i.e., who acted as facilitators during part one) conducted structured interviews with key staff. A four-section structured Needs Assessment Interview (NAI) schedule-based on a modified version of

Dr. McGilloway is a lecturer in the Department of Psychology, National University of Ireland, Maynooth, County Kildare, Ireland; and Dr. Donnelly; is a reader in the Department of Epidemiology and Public Health, School of Medicine, Queen's University, Belfast, Northern Ireland.

The authors thank the Interagency Group on Mental Health and Homelessness, which funded this study. They are also grateful to the hostel staff and mental health professionals who participated in the research. 
Wykes's Assessment of Need Questionnaire [5]—was completed for each resident by one of the mental health professionals in conjunction with one or more hostel or $\mathrm{B} \& \mathrm{~B}$ staff (one person was inadvertently excluded from the assessments). This scale, as opposed to the MRC Needs for Care Assessment Schedule [6], was chosen for its relative simplicity, brevity, and minimal training requirements. In Section One, staff indicate for which of eight types of accommodation they consider the resident best suited. The level of need for, and availability of, a number of health and social services (i.e., "no need," "under-used," "met need," or "unmet need") is assessed in Section Two. Section Three focuses on general mental health care; and the final section comprises a list of 28 services (medical, social, etc.) for which staff are asked to indicate current need and receipt.

\section{Results}

\section{Mental health service needs}

Mental health services were among the ten services considered to be most commonly needed by residents (see Figure 1). High levels of unmet need were also recorded for social activities (44 percent) and day-care provision (39 percent). GP services were the most widely received (65 percent, 107/164) of all services.

Only 44 percent $(73 / 164)$ of residents were receiving one or more mental health service(s). For example, 34 percent (56/164) needed, but were not in contact with, a mental health social worker (Figure 2). Only 8 percent (14/164) and 10 percent (16/164) of the group were seeing a CPN and psychiatrist, despite the fact that a further 30 percent (50/164) and 26 percent (43/164), respectively, were in need of these specialist services. However, social work services were received by proportionately fewer people than any of the other "key" services. Furthermore, staff reported that only 7 percent of residents $(11 / 164)$ were attending a psychiatric outpatient clinic, and a further 21 percent $(35 / 164)$ were in need of this service. Similarly, four people were attending a day hospital; but a further 12 people ( 7 percent) could, according to staff, benefit from day-hospital attendance (see Figure 2).

Most of the residents in need of mental health services had "moderate" to "severe" levels of impairment on the Rehabilitation Evaluation Hall \& Baker (REHAB) Scale [7], and the proportion in need of each service increased with greater levels of disability. For example, staff estimated that 30 percent $(25 / 83)$ of "community survivors" would have benefited from contact with a CPN, compared with 58 percent (18/31) of those in the "severely impaired" category. Need for most services was also significantly associated with the type of mental health problem. For example, proportionately more people who had a specific mental illness only (as opposed to those with alcohol and/or drug problems) needed to see a psychiatrist (47 percent vs. 10 percent, respectively; $\chi^{2}=28.47, \mathrm{df}=5, \mathrm{P}$ $<0.0001)$. 


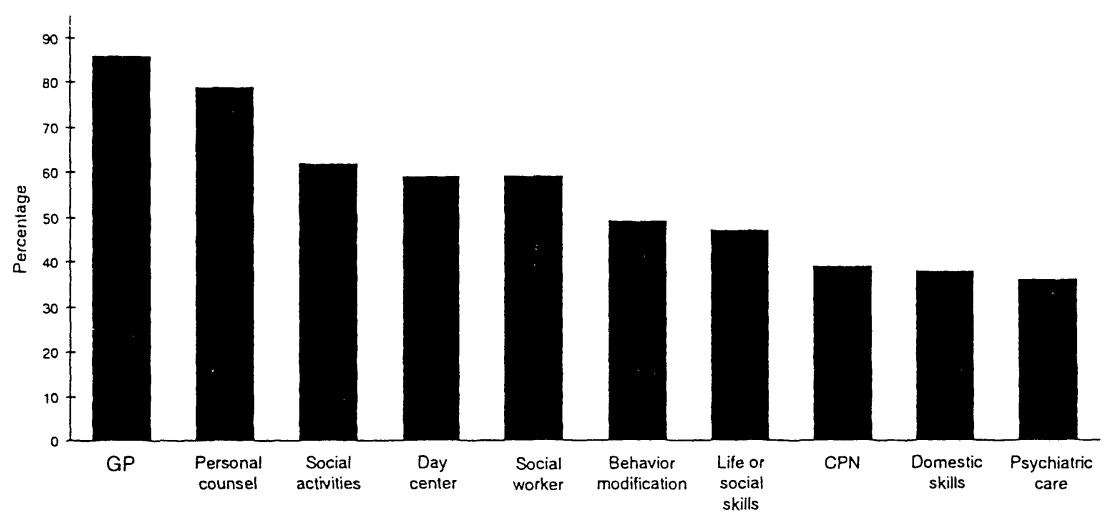

Type of service/intervention

Figure 1 . Ten services most commonly needed by residents.

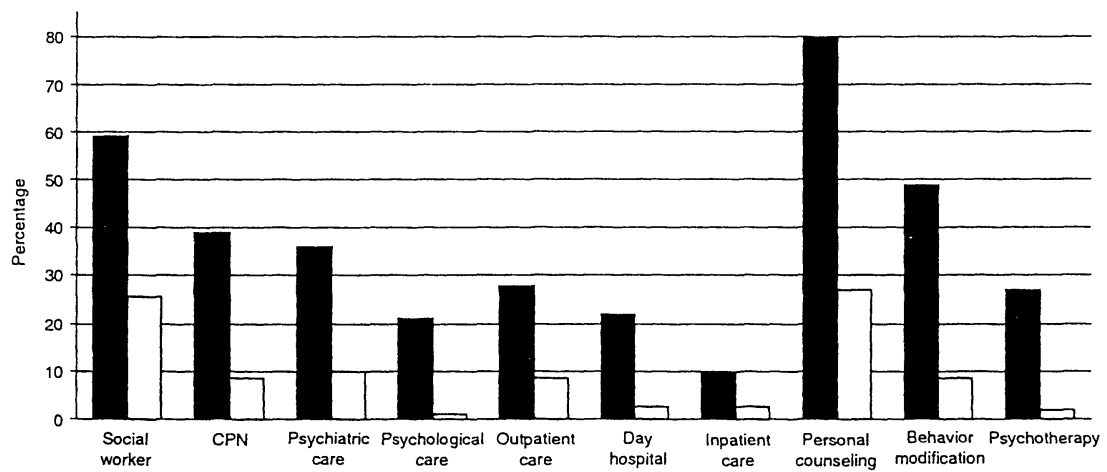

Type of mental health service/intervention

Figure 2. Staff-perceived need for and receipt of mental health services.

\section{Supervision of medication}

Approximately half (49 percent, 81/164) of the residents were taking regular medication for their mental health problem, most (74 percent, 60/81) of whom did so without supervision. Six people (7 percent) were resistant to supervision or refused to take medication. Eleven percent (10/81) had not had at least one review of their medication requirements during the previous year. Supervision needs were significantly associated $\left(\chi^{2}=35.42, \mathrm{df}=4, \mathrm{P}<0.0001\right)$ with the General Behaviour 
(GB) [7] category. For example, 76 percent (63/83) of "community survivors" required no supervision compared with 54 percent (27/50) and 23 percent (7/31), respectively, of "moderately" and "severely" impaired residents.

\section{Accommodation needs and levels of functioning/dependency}

Fifty-three percent (87/164) of residents were, according to staff, best suited for some form of independent living (see the table); but most of the remainder (64/77) required more supportive accommodation. These staff-perceived accommodation needs are consistent with clinical judgments about the types of accommodation considered suitable for people with different levels of mental disability [7]. For example, there was a significant relationship $\left(\chi^{2}=26.0, \mathrm{df}=8, \mathrm{P}<0.01\right)$ between the REHAB General Behavior (GB) category and the type of accommodation considered by staff to be most appropriate; and 70 percent (38/54) of residents who required shared, fully staffed community accommodation (51) or institutionaltype care (3) scored above the cutoff of 40 .

\section{Discussion}

To our knowledge, this is the first comparatively large-scale study of the service needs of single homeless people suffering from mental ill health. Although the design of the study may be less sophisticated than, for example, the work by Hogg $\&$ Marshall [8], it was, nonetheless, conducted on a large scale; and the findings, therefore, are more likely to be representative than the few previous surveys. It is important, however, to be aware of the limitations of the study in view of the problems of rating need for behavioral interventions in hostels for the homeless and of excluding residents' views [8]. (It is worth noting that the views of a small, randomly selected sample of 28 residents [ 17 percent] were elicited during interviews with a former homeless person [McGilloway \& Donnelly (9)].)

Nonetheless, although the assessments were staff based, the method provides useful global estimates of service need. Moreover, the validity of the needs assessment is based on a set of interrelated activities such as the structured training program for hostel staff (see the previous paper), the completion of self-report measures for each resident, and the joint assessment (by a mental health professional and a hostel worker) of service needs. Furthermore, the various sources of data are internally consistent. For example, the significant association between service needs and REHAB scores indicates staff knowledge of, and sensitivity to, the extent of impairment among their residents.

The results suggest that many people have high levels of need that are not being met by existing services. The comparatively high level of contact with GP services is consistent with previous findings [10-12] that indicate an increased risk of physical illness among the homeless and high levels of comorbidity of physical and mental illness. No information was available from our study on the number of 


\section{Staff-perceived Accommodation Needs}

\begin{tabular}{lcc} 
Type of accommodation & Number of residents & $\%$ \\
\hline $\begin{array}{l}\text { Independent living (house/flat/bedsit) } \\
\text { Independent living with minimal support } \\
\text { (resident visited regularly by someone } \\
\text { experienced in providing type of support } \\
\text { required) }\end{array}$ & 34 & 21 \\
$\begin{array}{l}\text { Independent living with fuller support (resident } \\
\text { visited by housing support worker and } \\
\text { receives regular domiciliary backup from } \\
\text { members of the community psychiatric team } \\
\text { and social services) }\end{array}$ & 30 & 18 \\
$\begin{array}{l}\text { Shared accommodation (e.g., group home) } \\
\text { without support }\end{array}$ & 23 & \\
$\begin{array}{l}\text { Shared accommodation with nonresidential } \\
\text { support (residents visited regularly by member[s] } \\
\text { of psychiatric team) }\end{array}$ & 9 & 14 \\
$\begin{array}{l}\text { Shared accommodation with minimal staffing } \\
\text { (support staff during the day; unstaffed at night) }\end{array}$ & 13 & 1 \\
$\begin{array}{l}\text { Shared accommodation with full (24-hour) } \\
\text { support (possible supervision of self-care, } \\
\text { meals, and other daily activities) }\end{array}$ & 51 & 5 \\
$\begin{array}{l}\text { Institutional care } \\
\begin{array}{l}\text { Total } \\
\hline\end{array}\end{array}$ & 3 & 2 \\
\hline
\end{tabular}

people permanently on GP lists and, therefore, to what extent they were receiving continuity of care. This is an important point because, for many homeless people, GPs often provide the first contact with mainstream health and social services and are ideally placed to assuage any fears or suspicions about health professionals. They should, therefore, be targeted in any promotional or training activities that specifically address the needs of the homeless mentally ill.

Single homeless people with mental ill health also have comparatively high levels of need for services provided by social workers, CPNs, and psychiatrists. However, the highest levels of need, overall, were found to be for specific, timeintensive interventions such as personal counseling and, consistent with other research [8], behavioral therapy. (The mental health professionals provided guidance to staff and were able, therefore, to explain, if necessary, the distinction between 
personal counseling, behavioral therapy, and alternative forms of care.) Hostel staff were also performing duties outside their remit in that, for a small number of people, they were supervising the medication requirements.

The findings point toward serious gaps in mental health service provision, as over half of the residents were not receiving such services. Furthermore, the high levels of unmet need for social activities indicate-in line with the available evidence $[8,12]$-that although many of the group may be incapable of work, a large proportion do require a structured program of social activities. This highlights the social isolation commonly observed among homeless people (and likely to be exacerbated by chronic mental health problems).

The residents in this study require a variety of housing options that are consistent, for the most part, with the REHAB categorizations. Large proportions of residents also require life/social skills and/or domestic skills training and are better suited, therefore, to more specialist forms of accommodation-at least in the short term - where these kinds of activities can be tailored to their needs and routinely offered to promote skill development and autonomy. For example, residents with alcohol problems may experience great difficulty in finding and keeping suitable accommodation, and may also be more likely to lose contact with caring agencies [13].

It was not possible in this study to assess the extent to which high levels of unmet need indicate inadequate provision because homeless people may, on occasion, be reluctant to accept professional help. The need to engage homeless people in services is an important issue often cited to explain their generally low acceptance of mainstream services. For example, homeless hostel residents may perceive service providers as intimidating and/or lack the motivation to attend to their mental or physical health, about which they may also have low expectations [10] and over which basic requirements such as housing and income tend to take precedence [2].

Health professionals should, therefore, attempt to build trusting relationships with their homeless clients as a critical first step toward more conventional treatment and care. There are some indications from this study that the inadequacy of present service provision may stem, at least in part, from the type and nature of services rather than the absence of services per se. For example, the present demarcation of community mental health and primary care services within the United Kingdom may result in fragmented (or no) service provision for homeless people with physical and mental health-care needs.

Adequate service provision should incorporate a range of affordable housing (e.g., similar to the London Homeless Mentally Ill Initiative [4]), linked to supportive, multidisciplinary (mainstream and specialized) services that provide both mental and physical health care and rehabilitation. Options for service changebased on the findings of this and other studies and on key documentation [14] and the views of local agency representatives-might include: (a) mental health awareness and education programs for all staff working with homeless people, including GPs; $(b)$ involvement of service-users in the consultation process; $(c)$ an 
assessment of existing service provision to inform future professional roles and practices; $(d)$ a designated multidisciplinary "rapid response" service for homeless mentally ill people (and a reconfiguration of existing services); $(e)$ training for specialist team members in substance abuse; $(f)$ development of specialist accommodation unit(s); and $(g)$ increased provision of day care. It is worth noting that, following dissemination of the research reported here [9], a Homeless Support Team has been set up in Belfast.

Finally, although future research is needed to inform the systematic planning and implementation of services for homeless people with mental health problems, health and social service planners and providers should, in the meantime, be prepared to take risks in order to devise an innovative, effective, and nonstigmatizing service response for this doubly disadvantaged group of people.

\section{References}

1. Scott, J. (1993) Homelessness and mental illness. British Journal of Psychiatry, 162,314 .

2. Moxley, D.P., \& Freddolino, P.P. (1991) Needs of homeless people coping with psychiatric problems: Findings from an innovative advocacy project. Health and Social Work, 16, 19.

3. Hamid, W.A., Wykes, T., \& Stansfeld, S. (1993) The homeless mentally ill: Myths and realities. International Journal of Social Psychiatry, 38, 237.

4. Craig, T., Bayliss, E., Klein, O., Manning, P.. \& Reader, L. (1995) The homeless mentally ill initiative. London: Department of Health.

5. Bowling, A., \& Parkman, S. (1993) A study of the needs of users of the psychiatric services in City and Hackney, with particular reference to those with a diagnosis of schizophrenia. City and Hackney District Health Authority (unpublished study).

6. Brewin, C.R., Wing, J.K., Mangen, S.P., Brugha, T.S., \& MacCarthy, B. (1987) Principles and practice of measuring needs in the long-term mentally ill: The MRC Needs for Care Assessment. Psychological Medicine, 17, 971.

7. Baker, R., \& Hall, J.N. (1994) Users manual for Rehabilitation Evaluation Hall and Baker. Aberdeen: Vine Publishing.

8. Hogg, L.I., \& Marshall, M. (1992) Can we measure need in the homeless mentally ill? Using the MRC Needs for Care Assessment in hostels for the homeless. Psychological Medicine, 22, 1027.

9. McGilloway, S., \& Donnelly, M. (1996) Don't look away: Homelessness and mental health in Belfast. Belfast: Council for the Homeless (NI).

10. Williams, S., \& Allen, I. (1989) Health care for single homeless people. London: Policy Studies Institute.

11. George, S.L., Shanks, N.J., \& Westlake, L. (1991) Census of single homeless people in Sheffield. British Medical Journal, 302, 1387.

12. Gill, B., Meltzer, H., Hinds, K., \& Pettigrew, M. (1996) Psychiatric morbidity among homeless people (OPCS Surveys of Psychiatric Morbidity in Great Britain, Report 7). London: HMSO.

13. Marshall, M., Nehring, J., Taylor, C., \& Gath, D. (1994) Characteristics of homeless mentally ill people who lose contact with caring agencies. Irish Journal of Psychological Medicine, 11, 160.

14. NHS Health Advisory Service (1995) A place in mind. Commissioning and providing mental health services for people who are homeless. London: HMSO. 